\title{
Monitoring asthma in childhood: symptoms, exacerbations and quality of life
}

\author{
Paul L.P. Brand ${ }^{1,2}$, Mika J. Mäkelä3 ${ }^{3}$ Stanley J. Szefler ${ }^{4}$, Thomas Frischer ${ }^{5}$ and \\ David Price $^{6}$ on behalf of the ERS Task Force Monitoring Asthma in Children ${ }^{7}$
}

\begin{abstract}
Affiliations: ${ }^{1}$ Princess Amalia Children's Centre, Isala Hospital, Zwolle, The Netherlands. ${ }^{2}$ UMCG Postgraduate School of Medicine, University Medical Centre and University of Groningen, Groningen, The Netherlands. ${ }^{3}$ Skin and Allergy Hospital, Helsinki University Hospital, Helsinki, Finland. ${ }^{4}$ Children's Hospital Colorado and University of Colorado Denver School of Medicine, Denver, CO, USA. ${ }^{5}$ Dept of Paediatrics and Paediatric Surgery, Wilhelminenspital, Vienna, Austria. ${ }^{6}$ Dept of Primary Care Respiratory Medicine, Academic Primary Care, Division of Applied Health Sciences, University of Aberdeen, Aberdeen, UK. ${ }^{7} \mathrm{~A}$ full list of the ERS Task Force Monitoring Asthma in Children members and their affiliations can be found in the acknowledgements section.
\end{abstract}

Correspondence: Paul L.P. Brand, Dept of Paediatrics, Princess Amalia Children's Centre, Isala Hospital, PO Box 10400, Zwolle 8000 GK, The Netherlands. E-mail: p.l.p.brandQisala.nl

ABSTRACT Monitoring asthma in children in clinical practice is primarily performed by reviewing disease activity (daytime and night-time symptoms, use of reliever medication, exacerbations requiring frequent use of reliever medication and urgent visits to the healthcare professional) and the impact of the disease on children's daily activities, including sports and play, in a clinical interview. In such an interview, most task force members also discuss adherence to maintenance therapy and the patients' (and parents') views and beliefs on the goals of treatment and the amount of treatment required to achieve those goals. Composite asthma control and quality of life measures, although potentially useful in research, have limited value in clinical practice because they have a short recall window and do not cover the entire spectrum of asthma control. Telemonitoring of children with asthma cannot replace face-to-face follow-up and monitoring because there is no evidence that it is associated with improved health outcomes.

$@$ ERSpublications

To monitor asthma control in children interviewing the child and parents is preferred over composite control scores http://ow.ly/JbqnR

\section{Introduction}

The ultimate goal of asthma treatment is to achieve and maintain clinical control and reduce future risks to the patient. To reach this goal in children with asthma, ongoing monitoring is essential. Recently, a European Respiratory Society Task Force on Monitoring Asthma in Childhood was published [1].

Although asthma guidelines place a strong emphasis on monitoring asthma control, there is no gold standard for asthma control. The Global Initiative for Asthma (GINA) proposes to define levels of asthma control based on clinical manifestations, forced expiratory volume in $1 \mathrm{~s}$ (FEV1) and expected future risk, and classifies patients as well-controlled, partly controlled or uncontrolled [2]. Similarly, the British Thoracic Society (BTS) guidelines for asthma control are based on clinical manifestations and FEV1 [3]. The National Asthma Education and Prevention Programme (NAEPP) defines control as "the degree to which the manifestations of asthma are minimized by therapeutic interventions and the goals of therapy are met" [4].

This is a supporting document of the ERS Task Force Monitoring Asthma in Children published in the European Respiratory Journal: Pijnenburg MW, Baraldi E, Brand PLP, et al. Monitoring asthma in children. Eur Respir J 2015; 45: 906-925.

Received: May 142014 | Accepted after revision: July 152014

Conflict of interest: Disclosures can be found alongside the online version of this article at err.ersjournals.com

Provenance: Submitted article, peer reviewed.

Copyright OERS 2015. ERR articles are open access and distributed under the terms of the Creative Commons Attribution Non-Commercial Licence 4.0. 
The aims of this review are to provide an in-depth discussion of the evidence for the usefulness of different tools available to monitor symptoms, exacerbations of asthma and quality of life (QoL) in children with asthma. In particular, we will discuss monitoring in view of appropriateness in different age groups. In this issue of the European Respiratory Review, three other articles will address general considerations on monitoring asthma in children, lung function and inflammatory markers, and management-related issues [5-7].

After establishing the diagnosis and agreeing on a treatment plan, children with asthma need to be followed up regularly to allow adequate provision of self-management education [8]. This usually takes at least two educational and instructional sessions, in which children and parents are encouraged to express concerns, questions and beliefs; in addition, inhalation techniques are taught and checked. Afterwards, most task force members will review the patient at least twice a year to discuss the degree of asthma control achieved and to evaluate whether maintenance treatment should be modified accordingly.

\section{Monitoring symptoms}

The key symptom of asthma is wheeze, caused by intrathoracic airway narrowing. This is usually accompanied by shortness of breath, chest tightness and cough (table 1). For patients, the things they hate most about their asthma, apart from having to take medication on a daily basis, are asthma attacks and the limitations asthma imposes on their daily activities including sports and play [9].

Focusing on such patient-centred outcomes during follow-up may be enhanced by starting the consultation by asking "What is useful for you to talk about today?", instead of the usual "How has your asthma been lately?" This can be followed by asking for specific symptoms (table 1). A review of reliever medication use is recommended in asthma guidelines as an expression of asthma control. Most task force members believe that a review of the much more important daily use of controller medication is of value at every follow-up visit [10].

Symptoms (including limitation of activities such as exercise and play) and rescue medication use are distinct domains in the clinical expression of asthma, independent from exacerbations, lung function and inflammation [11]. Children vary considerably in the degree of airway narrowing they perceive as dyspnoea of sufficient severity to prompt the use of reliever therapy [12]. It is likely that psychological factors, including anxiety and depression, are related to the burden imposed on the patient by symptoms of asthma, influencing their expression and perceived severity and impact [13]. Most asthma trials use diaries to monitor symptoms, but the evidence does not support the use of such diaries in clinical practice [14]. In addition, daily diaries in asthma have been shown to be unreliable, at least where peak flow is concerned [15]. In summary, it is current practice to ask questions on symptoms listed in table 1, focusing on patient-centred outcomes and medication use (both daily controller and reliever medication) at all visits.

\section{Composite asthma control scores}

Since the concept of asthma control has been introduced as a key feature in asthma guidelines, numerous attempts have been made to capture it in a single numerical value.

\section{TABLE 1 Symptoms and consequences of asthma disease activity}

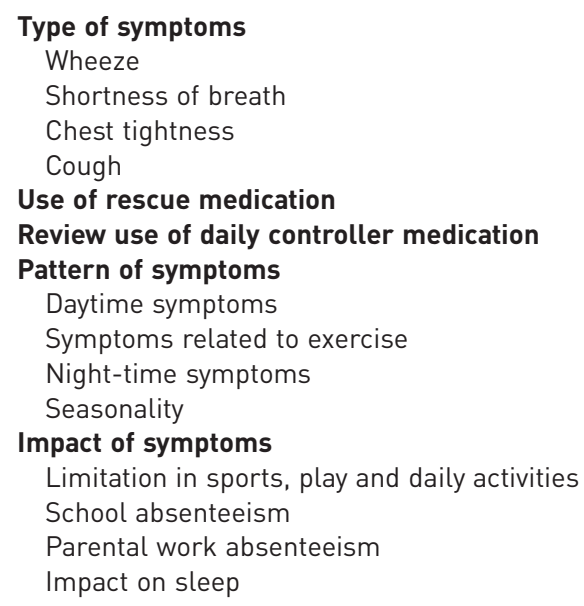


TABLE 2 Comparison of items in the asthma control test (ACT), childhood ACT and asthma control questionnaire (ACQ)

\begin{tabular}{lccc} 
Item & ACT & Childhood ACT & ACQ \\
\hline $\begin{array}{l}\text { Nocturnal awakening } \\
\text { Severity of nocturnal symptoms }\end{array}$ & + & + (child and parent) & + \\
Limitation of daily activities & + & + (child) & + \\
$\begin{array}{l}\text { Shortness of breath } \\
\text { Wheeze }\end{array}$ & + & + (parent) & + \\
$\begin{array}{l}\text { Use of rescue medication } \\
\text { Self-rated asthma control }\end{array}$ & + & + (child) & + \\
Cough & + & + (child) \\
Daytime asthma symptoms & & + (parent) & + \\
\hline
\end{tabular}

+ : indicates the item is incorporated into the score.

The full range of available paediatric composite asthma control scores has been reviewed elsewhere [16]. The two instruments with the most extensively reported validation are the (childhood) asthma control test, ACT or C-ACT [17], and the asthma control questionnaire (ACQ) [18]. These are compared in table 2. The ACT contains five items, with a recall window of 4 weeks. There is a separate version for children aged 4-12 years (the C-ACT), which consists of four pictorial items that are scored by the children themselves and three verbal items that are scored by the parents. One should be aware that children tend to report their asthma control to be significantly lower than their parents $[19,20]$. The ACQ contains six items with a recall window of 1 week; this is supplemented by measurement of FEV1 as a percentage of predicted ("the seventh question") [18]. Two novel composite asthma control scores take exacerbations into account: the Test for Respiratory and Asthma Control in Kids (TRACK) and the Composite Asthma Severity Index (CASI) [21, 22]. This is important because most symptoms captured in composite asthma control scores occur only, or most severely, during exacerbations, limiting the ability of asthma control scores to capture variations in control over a brief recall window during which no exacerbations occur.

Poor asthma control, as measured by the ACT, C-ACT or ACQ, is associated with reduced lung function, increased risk of exacerbations and elevated exhaled nitric oxide fraction, and is lower in children not regularly using inhaled corticosteroid maintenance therapy [17, 18, 23-27]. Children with asthma and allergic rhinitis have poorer asthma control and a higher risk of exacerbations than those without allergic rhinitis $[28,29]$. Children whose parents are concerned about the usefulness and side-effects of inhaled corticosteroid therapy also have poorer asthma control [30], and this association is caused by poor adherence to inhaled corticosteroids [31]. Follow-up studies have shown that changes in composite measures of asthma control reflect changes in the overall clinical assessment of asthma control by physicians, and the need to step up therapy [32]. No studies have assessed whether repeated structured assessment of asthma control by composite control measures helps to improve asthma control during long-term management and follow-up.

Although the concept of a composite asthma control score, which captures overall asthma control into a single numerical value, is intuitively appealing, it is also a contradiction in terms, because it is universally agreed that asthma control is a multidimensional construct [16]. Specifically, it has been recognised that asthma control should encompass both current impairment and future risk of exacerbations [33, 34]. A recent follow-up study in children showed that the degree of asthma control, as assessed by composite asthma control measures, changes over time and shows variable concordance with the risk of exacerbations [35, 36].

Despite their relatively well-documented validation, the ACT and ACQ share three drawbacks which limit their usefulness in clinical practice (table 3). Although the short recall window facilitates reliable recollection of asthma events that have occurred recently, it fails to represent the variable nature of the

TABLE 3 Limitations of using composite measures of asthma control

Short recall window: 1-4 weeks

Do not take asthma exacerbations into account, except TRACK and CASI

Cover only part of the asthma control spectrum (table 1)

TRACK: Test for Respiratory and Asthma Control in Kids; CASI: Composite Asthma Severity Index. 
disease. Children may be excellently controlled during one period (or season), and then have much more problematic asthma during another. In addition, asthma exacerbations occur in children with both good and poor short-term asthma control [37-40]. Exacerbations, an important component of asthma control (table 1), are not covered in the ACT, C-ACT and ACQ. This may explain why the agreement between asthma control as assessed by ACT or ACQ, as compared to an assessment using BTS or GINA guidelines, is poor $[19,41]$. Specifically, ACT scores appear to underestimate the level of asthma control, as defined by GINA [41].

All task force members assess asthma control during an interview, which may be supplemented by a composite asthma control score to help practitioners cover the range of symptoms and the impact on QoL.

Future research should focus on the: usefulness of composite asthma control scores in improving asthma control in primary and secondary care; external validation and reproducibility of cut-off points in different populations; and comparison of scores with the patient's perception and doctor's assessment of asthma control, and such studies may include lung function and assessment of airway inflammation.

\section{e-health and telemonitoring}

A number of studies have examined the impact of guided self-management by mobile phones or web-based platforms on asthma control. These were summarised in a recent Cochrane meta-analysis of 21 studies in adults and children. In this review, e-health initiatives did not improve patients' QoL or reduce exacerbation and hospitalisation rates in children [42]. At present, e-health initiatives are not routinely used in the clinical care of children with asthma. However, differences in study design, the patients included and the type and frequency of interventions makes comparisons of studies difficult, and future studies might focus on specific patient groups who may indeed benefit from specific e-health initiatives.

\section{Exacerbations}

Asthma exacerbations requiring urgent medical care, hospitalisation or the use of an oral corticosteroid course constitute one of the most troublesome aspects of asthma to patients [19], and severe exacerbations can be life threatening.

Most asthma exacerbations in children are triggered by viral upper respiratory tract infections [37], but they also occur after exposure to allergens or irritants [43]. The risk of asthma exacerbations is increased in children with poor adherence to maintenance therapy, poor asthma control and elevated exhaled nitric oxide levels, although none of these factors reliably predicts future exacerbation risk [44-47].

All task force members, as supported by guidelines, actively review exacerbations in addition to asthma control at each consultation in terms of severity, frequency and management $[2,3]$.

\section{Quality of life}

A range of paediatric asthma QoL instruments have been developed, encompassing the impact of asthma on children's or their parents' lives. These have been reviewed in detail elsewhere [48]. The instruments have been validated (internal consistency, reliability and concurrent associations with other disease outcomes), but all suffer from psychometric or generalisability limitations [48]. Although QoL correlates with poor asthma control and reduced lung function $[49,50]$, children with similar degrees of asthma control or lung function impairment show considerable QoL differences, which is partly explained by psychological problems, anxiety and depression [51, 52]. There is consensus that QoL instruments in childhood asthma provide independent additional information on disease status, complementing symptom scores and lung function, and have been recommended as a potentially useful additional outcome parameter to assess response to longer term treatment trials [3, 53]. No studies have assessed whether asthma management based on routine care plus QoL monitoring is superior to routine asthma management in improving asthma control and reducing exacerbations and limitations in sports and play.

Paediatric asthma QoL questionnaires contain between 15 and 48 items, and take between 8 and 20 min to complete [48]. If such instruments are to be used in clinical practice, they are usually completed before the consultation takes place because they are too time-consuming to be part of the routine $10-15 \mathrm{~min}$ follow-up consultation of a child with asthma. Although the instruments are designed to measure the impact of asthma on daily life of children, they are primarily developed and suitable for research purposes. It is unknown how asthmatic children and their parents would feel if they were asked to complete the same QoL questionnaire repeatedly during long-term follow-up. The structured format of QoL questionnaires may reduce the desired tailor-made approach in exploring the impact of the disease on an individual child's life, and should therefore not replace a normal doctor-patient-parent conversation. An additional limitation is the cost involved in using copyrighted paediatric QoL questionnaires. 
TABLE 4 Monitoring tools in research and in clinical practice

Research too

Use in clinical

practice

Comments

\begin{tabular}{|c|c|c|c|}
\hline $\begin{array}{l}\text { Symptoms/limitation of activities/use of } \\
\text { reliever medication }\end{array}$ & Yes & Yes & $\begin{array}{l}\text { Also discuss adherence to maintenance } \\
\text { medication; ensure proper inhalation technique }\end{array}$ \\
\hline Exacerbations & Yes & Yes & $\begin{array}{c}\text { Review exacerbations that have occurred and } \\
\text { their potential triggers }\end{array}$ \\
\hline Composite asthma control measures, e.g. ACT or ACQ & Yes & No & $\begin{array}{l}\text { Short recall window do not take exacerbations } \\
\text { and exercise limitations into account }\end{array}$ \\
\hline
\end{tabular}

$\mathrm{ACT}$ : asthma control test; $\mathrm{ACQ}$ : asthma control questionnaire.

To date, routine monitoring of QoL in children with asthma does not take place. Studies assessing the usefulness of longitudinal QoL measures as monitoring tools are needed.

\section{Conclusion}

In table 4 the monitoring tools used in the research and clinical practice of symptoms, exacerbations and QoL are summarised. Monitoring asthma in children in clinical practice requires a careful review of the impact of the disease on children's daily activities, including sports and play (table 1). In addition, most task force members review adherence to maintenance therapy and the patients' (and parents') views and beliefs on the goals of treatment and the amount of treatment required to achieve those goals. Composite asthma control and QoL measures, although potentially useful in research, have limited value in clinical practice. At present, telemonitoring of children with asthma does not replace face-to-face follow-up and monitoring.

\section{Acknowledgements}

The Task Force members and their affiliations are as follows. Paul L.P. Brand: Princess Amalia Children's Centre, Isala Hospital, Zwolle, and UMCG Postgraduate School of Medicine, University Medical Centre and University of Groningen, Groningen, The Netherlands; Mika J. Mäkelä: Skin and Allergy Hospital, Helsinki University Hospital, Helsinki, Finland; Stanley J. Szefler: Children's Hospital Colorado and University of Colorado Denver School of Medicine, Denver, CO, USA; Thomas Frischer: Dept of Paediatrics and Paediatric Surgery, Wilhelminenspital, Vienna, Austria; David Price: Dept of Primary Care Respiratory Medicine, Academic Primary Care, Division of Applied Health Sciences, University of Aberdeen, Aberdeen, UK; Eugenio Baraldi: Women's and Children's Health Dept, Unit of Respiratory Medicine and Allergy, University of Padova, Padova, Italy; Kai-Hakon Carlsen: Dept of Paediatrics, Women and Children's Division, University of Oslo, and Oslo University Hospital, Oslo, Norway; Ernst Eber: Respiratory and Allergic Disease Division, Dept of Paediatrics and Adolescence Medicine, Medical University of Graz, Graz, Austria; Gunilla Hedlin: Dept of Women's and Children's Health and Centre for Allergy Research, Karolinska Institutet, and Astrid Lindgren Children's hospital, Stockholm, Sweden; Neeta Kulkarni: Leicestershire Partnership Trust and Dept of Infection, Immunity and Inflammation, University of Leicester, Leicester, UK; Christiane Lex: Dept of Paediatric Cardiology and Intensive Care Medicine, Division of Paediatric Respiratory Medicine, University Hospital Goettingen, Goettingen, Germany; Karin C. Lødrup Carlsen: Dept of Paediatrics, Women and Children's Division, Oslo University Hospital, and Dept of Paediatrics, Faculty of Medicine, University of Oslo, Oslo, Norway; Eva Mantzouranis: Dept of Paediatrics, University Hospital of Heraklion, University of Crete, Heraklion, Greece; Alexander Moeller: Division of Respiratory Medicine, University Children's Hospital Zurich, Zurich, Switzerland; Ian Pavord: Dept of Respiratory Medicine, University of Oxford, Oxford, UK; Giorgio Piacentini: Paediatric Section, Dept of Life and Reproduction Sciences, University of Verona, Verona, Italy; Mariëlle W. Pijnenburg: Dept Paediatrics/Paediatric Respiratory Medicine, Erasmus MC - Sophia Children's Hospital, Rotterdam, The Netherlands; Bart L. Rottier: Dept of Pediatric Pulmonology and Allergology, GRIAC Research Institute, University Medical Center Groningen, University of Groningen, Groningen, The Netherlands; Sejal Saglani: Leukocyte Biology and Respiratory Paediatrics, National Heart and Lung Institute, Imperial College London, London, UK; Peter D. Sly: Queensland Children's Medical Research Institute, The University of Queensland, Brisbane, Australia; Steve Turner: Dept of Paediatrics, University of Aberdeen, Aberdeen, UK; Edwina Wooler: Royal Alexandra Children's Hospital, Brighton, UK.

\section{References}

$1 \quad$ Pijnenburg MW, Baraldi E, Brand PLP, et al. Monitoring asthma in children. Eur Respir J 2015; 45: 906-925.

2 Global Initiative for Asthma. Global Strategy for Asthma Management and Prevention. www.ginasthma.org/local/ uploads/files/GINA_Report_2014_Aug12.pdf Date last updated: 2014.

3 British Thoracic Society, Scottish Intercollegiate Guidelines Network. British guideline on the management of asthma. Thorax 2008; 63: Suppl. 4, iv1-i121.

4 National Asthma Education and Prevention Program. Expert Panel Report 3 (EPR-3): Guidelines for the diagnosis and management of asthma - summary report 2007. J Allergy Clin Immunol 2007; 120: Suppl. 5, S94-S138.

5 Lødrup Carlsen KC, Pijnenburg MW. Monitoring asthma in childhood. Eur Respir Rev 2015; 24: 178-186.

6 Moeller A, Carlsen K-H, Sly PD, et al. Monitoring asthma in childhood: lung function, bronchial responsiveness and inflammation. Eur Respir Rev 2015; 24: 204-215. 
Rottier BL, Eber E, Hedlin G, et al. Monitoring asthma in childhood: management-related issues. Eur Respir Rev 2015; 24: 194-203.

8 Klok T, de Groot EP, Brouwer AFJ, et al. Follow-up of children with asthma. In: Carlsen K-H, Gerritsen J, eds. Paediatric Asthma. ERS Monogr 2012; 56: 210-223.

9 Wildhaber J, Carroll WD, Brand PL. Global impact of asthma on children and adolescents' daily lives: the room to breathe survey. Pediatr Pulmonol 2012; 47: 346-357.

10 Stevenson FA, Cox K, Britten N, et al. A systematic review of the research on communication between patients and health care professionals about medicines: the consequences for concordance. Health Expect 2004; 7: 235-245.

11 Holt EW, Cook EF, Covar RA, et al. Identifying the components of asthma health status in children with mild to moderate asthma. J Allergy Clin Immunol 2008; 121: 1175-1180.

12 Brouwer AFJ, Brand PL, Roorda RJ, et al. Airway obstruction at time of symptoms prompting use of reliever therapy in children with asthma. Acta Paediatrica 2010; 99: 871-876.

13 Richardson LP, Lozano P, Russo J, et al. Asthma symptom burden: relationship to asthma severity and anxiety and depression symptoms. Pediatrics 2006; 118: 1042-1051.

14 Arga M, Sahbaz H, Bakirtas A, et al. Does self-monitoring by means of symptom diaries improve asthma control in children? J Asthma 2014; 51: 299-305.

15 Kamps AW, Roorda RJ, Brand PL. Peak flow diaries in childhood asthma are unreliable. Thorax 2001; 56: 180-182.

16 Cloutier MM, Schatz M, Castro M, et al. Asthma outcomes: composite scores of asthma control. J Allergy Clin Immun 2012; 129: Suppl. 4, S24-S33.

17 Liu AH, Zeiger R, Sorkness C, et al. Development and cross-sectional validation of the childhood asthma control test. J Allergy Clin Immunol 2007; 119: 817-825.

18 Juniper EF, Gruffydd-Jones K, Ward S, et al. Asthma Control Questionnaire in children: validation, measurement properties, interpretation. Eur Respir J 2010; 36: 1410-1416.

19 Carroll WD, Wildhaber J, Brand PL. Parent misperception of control in childhood/adolescent asthma: the Room to Breathe survey. Eur Respir J 2012; 39: 90-96.

20 Voorend-van Bergen S, Brackel H, Caudri D, et al. Assessment of asthma control by children and parents. Eur Respir J 2013; 41: 233-234.

21 Murphy KR, Zeiger RS, Kosinski M, et al. Test for respiratory and asthma control in kids (TRACK): a caregiver-completed questionnaire for preschool-aged children. J Allergy Clin Immunol 2009; 123: 833-839.

22 Wildfire JJ, Gergen PJ, Sorkness CA, et al. Development and validation of the composite asthma severity index an outcome measure for use in children and adolescents. J Allergy Clin Immunol 2012; 129: 694-701.

23 de Blic J, Boucot I, Pribil C, et al. Control of asthma in children: still unacceptable? A French cross-sectional study. Respir Med 2009; 103: 1383-1391.

24 Ito Y, Adachi Y, Itazawa T, et al. Association between the results of the childhood asthma control test and objective parameters in asthmatic children. J Asthma 2011; 48: 1076-1080.

25 Piacentini GL, Peroni DG, Bodini A, et al. Childhood asthma control test and airway inflammation evaluation in asthmatic children. Allergy 2009; 64: 1753-1757.

26 Stanford RH, Gilsenan AW, Ziemiecki R, et al. Predictors of uncontrolled asthma in adult and pediatric patients: analysis of the Asthma Control Characteristics and Prevalence Survey Studies (ACCESS). J Asthma 2010; 47: 257-262.

27 van Dalen C, Harding E, Parkin J, et al. Suitability of forced expiratory volume in 1 second/forced vital capacity $v s$ percentage of predicted forced expiratory volume in 1 second for the classification of asthma severity in adolescents. Arch Pediat Adol Med 2008; 162: 1169-1174.

28 de Groot EP, Nijkamp A, Duiverman EJ, et al. Allergic rhinitis is associated with poor asthma control in children with asthma. Thorax 2012; 67: 582-587.

29 Thomas M, Kocevar VS, Zhang QY, et al. Asthma-related health care resource use among asthmatic children with and without concomitant allergic rhinitis. Pediatrics 2005; 115: 129-134.

30 Koster ES, Wijga AH, Koppelman GH, et al. Uncontrolled asthma at age 8: the importance of parental perception towards medication. Pediatr Allergy Immunol 2011; 22: 462-468.

31 Kaptein AA, Klok T, Moss-Morris R, et al. Illness perceptions: impact on self-management and control in asthma. Curr Opin Allergy Clin Immunol 2010; 10: 194-199.

32 Chipps B, Zeiger RS, Murphy K, et al. Longitudinal validation of the Test for Respiratory and Asthma Control in Kids in Pediatric Practices. Pediatrics 2011; 127: e737-e747.

33 Bateman ED, Reddel HK, Eriksson G, et al. Overall asthma control: the relationship between current control and future risk. J Allergy Clin Immun 2010; 125: 600-608.

34 Bousquet J, Mantzouranis E, Cruz AA, et al. Uniform definition of asthma severity, control, and exacerbations: document presented for the World Health Organization Consultation on Severe Asthma. J Allergy Clin Immun 2010; 126: 926-938.

35 Koster ES, Raaijmakers JA, Vijverberg SJ, et al. Limited agreement between current and long-term asthma control in children: the PACMAN cohort study. Pediatr Allergy Immol 2011; 22: 776-783.

36 Wu AC, Tantisira K, Li LL, et al. Predictors of symptoms are different from predictors of severe exacerbations from asthma in children. Chest 2011; 140: 100-107.

37 Jackson DJ, Sykes A, Mallia P, et al. Asthma exacerbations: origin, effect, and prevention. J Allergy Clin Immunol 2011; 128: 1165-1174.

38 Rosychuk RJ, Voaklander DC, Klassen TP, et al. Asthma presentations by children to emergency departments in a Canadian province: a population-based study. Pediatr Pulmonol 2010; 45: 985-992.

39 Covar RA, Szefler SJ, Zeiger RS, et al. Factors associated with asthma exacerbations during a long-term clinical trial of controller medications in children. J Allergy Clin Immunol 2008; 122: 741-747.

40 Forno E, Fuhlbrigge A, Soto-Quiros ME, et al. Risk factors and predictive clinical scores for asthma exacerbations in childhood. Chest 2010; 138: 1156-1165

41 Koolen BB, Pijnenburg MW, Brackel HJ et al. Comparing Global Initiative for Asthma (GINA) criteria with the Childhood Asthma Control Test (C-ACT) and Asthma Control Test (ACT). Eur Respir J 2011; 38: 561-566.

42 McLean S, Chandler D, Nurmatov U, et al. Telehealthcare for asthma: a Cochrane review. Can Med Assoc J 2011; 183: E733-E742. 
43 Sala KA, Carroll CL, Tang YS, et al. Factors associated with the development of severe asthma exacerbations in children. J Asthma 2011; 48: 558-564.

44 Fuhrman C, Dubus JC, Marguet C, et al. Hospitalizations for asthma in children are linked to undertreatment and insufficient asthma education. J Asthma 2011; 48: 565-571.

45 Ungar WJ, Paterson JM, Gomes T, et al. Relationship of asthma management, socioeconomic status, and medication insurance characteristics to exacerbation frequency in children with asthma. Ann Allergy Asthma Immunol 2011; 106: 17-23.

46 Visser CA, Brand PL. Does a single measurement of exhaled nitric oxide predict asthma exacerbations? Arch Dis Child 2011; 96: 781-782.

47 Williams LK, Peterson EL, Wells K, et al. Quantifying the proportion of severe asthma exacerbations attributable to inhaled corticosteroid nonadherence. J Allergy Clin Immunol 2011; 128: 1185-1191.

48 Wilson SR, Rand CS, Cabana MD, et al. Asthma outcomes: quality of life. J Allergy Clin Immunol 2012; 129: Suppl. 3, S88-S123.

49 Juniper EF, Guyatt GH, Feeny DH, et al. Measuring quality of life in the parents of children with asthma. Qual Life Res 1996; 5: 27-34.

50 Guilbert TW, Garris C, Jhingran P, et al. Asthma that is not well-controlled is associated with increased healthcare utilization and decreased quality of life. J Asthma 2011; 48: 126-132.

51 Goldbeck L, Koffmane K, Lecheler J, et al. Disease severity, mental health, and quality of life of children and adolescents with asthma. Pediatr Pulmonol 2007; 42: 15-22.

52 Annett RD, Bender BG, Lapidus J, et al. Predicting children's quality of life in an asthma clinical trial: what do children's reports tell us? J Pediatr 2001; 139: 854-861.

53 Williams J, Williams K. Asthma-specific quality of life questionnaires in children: are they useful and feasible in routine clinical practice? Pediatr Pulmonol 2003; 35: 114-118. 